DOCUMENTA

\title{
MEMÓRIAS DE UMA APRENDIZ INGÊNUA
}

Yonne Leite

Neste número de Mana, trazemos na seção

Documenta uma homenagem à nossa colega Yonne Leite, falecida em dezembro de 2014, através da republicação de sua apresentação no Seminário Roberto Cardoso de Oliveira, realizado no PPGAS/MN em março de 2007. Professora cuja atuação foi fundamental para a história de nosso programa e para a consolidação da Antropologia no Brasil, Yonne é aqui relembrada ao contar como surgiu seu interesse por línguas indígenas, e as subsequentes implicações.

Agradecemos à Bruna Franchetto, ex-aluna e co-organizadora do livro em que o artigo foi originalmente publicado, pela apresentação do texto, e à bolsista de iniciação Luísa Machado de Siqueira, pelo apoio na digitação e na formatação.

Renata Menezes, pela Editoria de Mana 


\section{Apresentação}

Antes de tudo, Yonne de Freitas Leite nos ensinou muito e agradeço por ela me ter dado a oportunidade ímpar de admirar as faces múltiplas e interconectadas de seu pensamento, as lições de estilo, metodológicas e teóricas, o compromisso político, a generosidade e a ética que marcaram a sua vida pessoal e profissional. Lições para todos, sobretudo para quem começa, querendo saber mais de um universo fascinante e cheio de descobertas a fazer.

Yonne foi personagem em destaque da história do desenvolvimento da linguística e dos estudos de línguas indígenas no Brasil, tendo sido uma das primeiras mulheres brasileiras na academia a realizar pesquisa de campo em área indígena. Nos seus cinquenta anos de trabalho no Museu Nacional, conviveu e colaborou com antropólogos e linguistas contemporâneos de relevo, orientou direta e indiretamente projetos, dissertações e teses de vários pesquisadores hoje atuantes. Como docente e pesquisadora, atuou no Departamento de Antropologia e no Programa de Pós-Graduação em Antropologia Social do Museu Nacional, Universidade Federal do Rio de Janeiro. Presidiu a Associação Brasileira de Linguística (Abralin, 1979-1981) e a Associação Brasileira de Antropologia (ABA, 1998-2000) e nunca deixou de tentar reiniciar um diálogo entre Linguística e Antropologia depois do fim do namoro estruturalista. Dizia que os colegas de trabalho no Programa de Pós-Graduação em Antropologia Social e no Setor de Linguística do Museu Nacional (UFRJ) "nunca a deixaram envelhecer".

O texto agora (re)publicado contém a contribuição de Yonne para a mesa redonda "A linguística antropológica: novos sujeitos e novos objetos", realizada no âmbito do Seminário FINEP Roberto Cardoso de Oliveira, Museu Nacional/UFRJ, de 28 a 30 de março de 2007. Foi um dos últimos textos de sua autoria divulgado e publicado, pela primeira vez, no livro Yonne de Freitas Leite. Línguas Indígenas: Memórias de uma pesquisa infinda, organizado por mim e por Thiago Coutinho-Silva (Leite 2012).

A palavra "memórias" conecta os títulos do livro/coletânea de 2012 e deste texto. Lá, como "memórias de uma pesquisa infinda", aqui, como "memórias de uma aprendiz ingênua". Bem sabemos que Yonne sempre foi uma aprendiz, já que manteve viva até o fim a sua sedenta curiosidade intelectual, assim como sabemos que atrás do adjetivo "ingênua" está toda a sinceridade e toda a nobre modéstia que caracterizaram a sua vida e a sua trajetória científica e acadêmica. Estas palavras também apontam para o seu constante exercício em relativizar não as suas seguranças intelectuais, mas a si mesma, sempre tentando se afastar do centro das atenções, sempre alertando para quão desagradáveis são os egos não domesticados. 
A inteligência de Yonne era atravessada por intuições geniais, rigor de raciocínio e de julgamento, generosidade e uma ironia às vezes áspera, mas sempre elegante e certeira. O adjetivo "infindo" está também no título de outra homenagem, publicada na revista Ciência Hoje em 2013 (Franchetto \& Vieira Leite 2013), agora qualificando a paixão que a linguista Yonne Leite nunca deixou em segundo plano ao investigar, falar e escrever sobre línguas indígenas, e também das ameaças que tanto rondam a sua sobrevivência como a de seus falantes.

No texto que se segue, Yonne rememora uma longa série de acasos que a levaram a estabelecer os primeiros contatos com a diversidade cultural e linguística brasileira, em particular com os Tapirapé, povo de língua tupi-guarani. Os então jovens antropólogos Luiz de Castro Faria e Roberto Cardoso de Oliveira e a antropologia estrutural a acompanhavam. A narrativa expõe o processo que, no Brasil, levou a linguística, "sob a égide da antropologia", a se desenvolver de disciplina optativa a disciplina obrigatória no currículo dos cursos de Letras. Posteriormente, ao deixar de ser considerada como um mero "instrumento" auxiliar, a linguística passou a ser tratada como um saber teórica e metodologicamente sólido e modelar, consolidando-se finalmente como um programa de pós-graduação.

Assim, Yonne narra, com seu estilo leve e preciso, o processo de criação do primeiro curso de pós-graduação em Linguística no Museu Nacional que, por razões diversas, acabou mudando para outros espaços institucionais e multiplicando-se. Foi testemunha dos primeiros passos da linguística no Brasil, da influência de Mattoso Câmara Jr., da chegada do paradigma chomskiano, que abria novas portas e janelas para arejar, numa subversão sadia, os já cansados referentes estruturalistas. A busca por um maior entendimento da teoria gerativa, que a fascinava, motivou a sua ida aos Estados Unidos para fazer doutorado junto a um grupo de jovens estudantes atraídos por novas ideias. De qualquer maneira, Yonne nunca foi uma adepta ortodoxa de qualquer corrente teórica, preferindo explorar a multiplicidade de ideias e de propostas que considerava adequadas e relevantes para alcançar a melhor análise possível dos dados empíricos que estavam em suas mãos. Os desafios da enorme tarefa de registrar e estudar as muitas línguas nativas ainda faladas no país a estimularam a colocar a formação de novos pesquisadores acima da ambição pessoal em perseguir fama e méritos superficiais.

Yonne rememora a sua pesquisa entre os Tapirapé, aos quais permaneceria fiel, as alegrias e os desafios das descobertas, a natureza profundamente humana do trabalho de campo, os momentos teóricos de seu caminho como linguista. Toda pesquisa é infinda, como dizia, já que uma língua é manancial 
para gerações de investigadores, um tesouro inesgotável, do qual um único indivíduo pode apenas desvelar alguns elementos e aspectos. Yonne nos deu insights imperdíveis das características da língua tapirapé e em comparação com outras línguas da família tupi-guarani, concluindo:

O que aprendi nesta tentativa de chegar a uma descrição a mais completa possível é que o fenômeno da linguagem é tão vasto, tão complexo que nem usando todas as teorias existentes se dá conta da totalidade de seus aspectos. Nem uma só pessoa. Acabou-se a mística do estruturalismo, em que bastava documentar, segmentar, arrolar e rotular e, pronto, lá se tinha a língua completa. Hoje se sabe que para se chegar a algum porto mais seguro é preciso ter perspectivas diferentes, testar várias hipóteses e teorias concorrentes e, mesmo que se tente unir todas essas perspectivas, muita coisa ainda ficará de fora.

Não posso deixar de expressar algumas considerações sobre o papel que Yonne representou, com renovadas dificuldades e superações, nos encontros e desencontros entre linguística e antropologia, pelo menos no cenário brasileiro. O texto "Língua e Cultura", ${ }^{1}$ de 1985 (em Franchetto \& Coutinho-Silva 2012), é um exemplo da atenção interdisciplinar e da clareza com as quais Yonne conseguia falar de temas complexos cheios de luzes e sombras, como os que estão na fronteira entre linguística e antropologia ou etnologia:

explorar esse mundo da linguagem em sala de aula, num mundo integrado de artes e letras, me parece uma aventura promissora. Não sei que surpresas estariam reservadas aos viajantes, nem sei ao certo o caminho a indicar. O que ofereço aqui nesta oportunidade é o desejo de um diálogo profícuo e algumas ideias para um debate que desejo vivo e caloroso.

Yonne falava da relação entre língua escrita e língua falada, mostrava como a linguística é o guia para a contemplação das formas lexicais e gramaticais que nos introduzem em conhecimentos, categorias cosmológicas e sociais. Neste mesmo ensaio, Yonne antecipava uma discussão de hoje nos palcos da linguística, ao pontuar as diferenças entre comunicação animal e linguagem humana, ressaltando a criatividade infinita desta última, através de mecanismos formais como a recursividade de estruturas autocontidas.

A saída da pós-graduação em Linguística do Museu Nacional para a Faculdade de Letras da UFRJ, na década de 1970, marcou, para Yonne, a separação entre os dois campos. Na antropologia, cada vez mais "cultural" e "social", a linguística sobreviveria apenas como utensílio, enquanto a antropologia seria definitivamente expurgada de uma linguística, cada vez 
mais "biológica", "cognitiva" ou apenas fracamente "sociológica". Para além dos rótulos híbridos, como "linguística antropológica", e da estreita ponte da "análise do discurso", este diálogo pode, e deveria, ser reinventado hoje com ousadia e criatividade em ambos os lados da fronteira.

Rio de Janeiro, 5 de junho de 2016.

Bruna Franchetto

\section{Nota}

${ }^{1}$ Texto apresentado no II Seminário de Educação Artística da Cidade do Rio de Janeiro, Secretaria Municipal de Educação e Cultura, Departamento Geral de Cultura, na conferência: “As Múltiplas Dimensões da Cultura" (1985).

\section{Referências bibliográficas}

FRANCHETTO, Bruna \& COUTINHO-SILVA, Thiago (orgs.). 2012. Yonne de Freitas Leite. Línguas indígenas: memórias de uma pesquisa infinda. Rio de Janeiro: Editora 7Letras.

FRANCHETTO, Bruna \& VIEIRA LEITE, Cassio. 2013. "Yonne de Freitas Leite - A linguista de paixão infinda". Ciência Hoje, 50(300):62-67, jan./fev. LEITE, Yonne. 2012. "Memórias de uma aprendiz ingênua". In: B. Franchetto; T. Coutinho-Silva (orgs.), Yonne de Freitas Leite. Línguas indígenas: memórias de uma pesquisa infinda. Rio de Janeiro: Editora 7Letras. 
As línguas são o melhor espelho do espírito humano

Gottfried-William Leibniz

É para mim uma grata lembrança participar do Seminário Roberto Cardoso de Oliveira e da mesa redonda A Linguística antropológica: novos sujeitos e novos objetos que nos permite conhecer os novos caminhos da Linguística Antropológica ou da Antropologia Linguística. Parece-me que sou uma das poucas sobreviventes da era Roberto Cardoso/Castro Faria. Alguns dos nossos colegas que aqui trabalharam e de quem nos tornamos amigos já se foram para sempre, outros seguiram outros caminhos, migraram para outras paragens, seguiram outros rumos. Não vou fazer daqui uma celebração da saudade ou de tristeza, vou apenas usar a minha qualificação de sobrevivente, de mais velha, ou melhor, sênior, para recordar um passado que é desconhecido para muitos que hoje trabalham no Museu Nacional.

Cheguei à Linguística não adjetivada, como tantos outros da minha geração, por mero acaso. Nem sabia que existiam índios no Brasil. Pensei que todos haviam morrido no processo de expansão e conquista do território brasileiro. Nos livros escolares tudo que se referia a índio estava no tempo passado: falavam uma língua tupi-guarani, moravam em tabas, tinham um cacique chamado morubixaba, eram antropófagos e pertenciam à raça vermelha. Aprendi nos meus primeiros anos da vida escolar que havia 4 raças: a branca, a negra, a amarela e a vermelha. Os brancos eram os colonizadores, os negros, os escravos, os amarelos, os japoneses, os chineses, conhecidos como asiáticos e os vermelhos, os índios.

Foi por causa da classificação "raça vermelha", fui chamada, pela primeira vez em minha vida, à diretoria do Colégio, onde fui duramente repreendida. Num teste em que se perguntava "qual a raça mais adiantada do mundo?" eu respondera sem titubear: "a raça mais adiantada do mundo é a raça vermelha". Pensaram que era deboche e a professora de geografia chorava copiosamente julgando que eu a estava desrespeitando. Eu não entendia o porquê daquela comoção. Minha resposta fora baseada da observação factual, o primeiro estágio da pesquisa científica. Era época da $2^{\mathrm{a}}$ guerra mundial, e marinheiros e oficiais da marinha americana aqui tinham uma base naval para proteger-nos contra os submarinos inimigos que rondariam nosso litoral. Passeavam por Copacabana, eram todos vermelhinhos, uma tonalidade totalmente diferente daquele vermelho dourado que se conseguia à força "torrando-se" nas praias nos meses de férias. Não se falava então em câncer de pele. E era o máximo se ter o tom avermelhado de preferência dourado. E, para mim, os americanos com seu vermelho róseo eram os mais 
adiantados, pois estavam ganhando a guerra, nos protegendo dos submarinos e ataques dos inimigos, tinham poderosos navios com enormes canhões e aviões de caça que riscavam nossos céus à noite, quando nossas janelas eram cobertas de panos pretos, o chamado blackout, obrigatório para quem morasse perto da orla. Tinham comidas enlatadas ótimas, inventaram a coca-cola e o cachorro quente, para não se falar dos maravilhosos sundaes, milk-shakes, waffles e pancakes com maple syrup. Para mim, a quem ensinaram que os índios eram vermelhos, os americanos eram índios, pois eram vermelhos e provenientes de um país muito adiantado tanto em iguarias, quanto em tecnologia. Os índios que vira nas gravuras dos livros didáticos eram meio amarronzados, andavam nus e enfeitados de penas. E o que eu conhecia mais era o que enfeitava uma caixa de biscoito chamado Aimoré, que tinha na tampa uma figura de um índio com uma enorme pena atravessada no nariz. Os americanos andavam bem vestidos e nos cinemas víamos suas casas lindíssimas, com jardins, automóveis, mulheres bem vestidas, aparelhos domésticos de vários tipos, a cobiça das donas de casa brasileiras, principalmente as travessas de pirex colorido. Passei pelo curso clássico e pela Faculdade de Letras, onde me formei em Letras Neolatinas ignorando a diversidade cultural e Linguística de nosso País.

Meu encontro com outros mundos se deu através da literatura. No curso de letras neolatinas tínhamos as disciplinas das literaturas brasileira, portuguesa, francesa, espanhola e latino-americana. Foi aí que meu mundo ultrapassou os limites da praia de Copacabana, mais especificamente, do Posto 4, e passou a ter horizontes muito mais amplos, indo da leitura e procura de entendimento do mundo subjacente à poesia dos trovadores medievais, aos autores latinos, portugueses, espanhóis e franceses, desde a Eneida de Virgilio às sagas dos Lusíadas de Camões, de Don Quixote de la Mancha de Cervantes, O Estrangeiro de Albert Camus, O Segundo Sexo e Memórias de uma Jovem bem comportada de Simone de Beauvoir, A náusea de Jean Paul Sartre até os livros paradisíacos de Pierre Loti, a poesia de Carlos Drummond de Andrade, Pedro Salinas e Federico García Lorca, entre muitos outros. Entrara, assim, em contato com culturas e línguas chamadas de "civilização", o mundo dos brancos.

Porém nada sabia do multiforme mundo das línguas e povos indígenas no Brasil, cuja existência só tive ciência, nos Estados Unidos da América, onde descobri também o que era Linguística. Havia a disciplina de Linguística na Faculdade de Letras, ministrada por Joaquim Mattoso Câmara Júnior, porém não fazia parte do currículo do curso de letras neolatinas, devido ao acúmulo de disciplinas obrigatórias: língua e literatura latina, língua e literatura francesa, língua e literatura italiana, língua e literatura espanhola, 
língua portuguesa, literatura portuguesa, literatura brasileira, literatura latino-americana, e para os que desejavam ser professores as disciplinas de fundamentos da psicologia, da filosofia, da biologia educacional, teoria do ensino e prática didática.

\section{O despertar para um outro Brasil}

Foi num curso de verão em 1968, na Universidade de Michigan, que tive o primeiro contacto com a Linguística e a existência de línguas indígenas no Brasil. Ao fazer exercícios de fonologia nas aulas de introdução à Linguística, me deparei com dados do Maxakali, denominação seguida da localização Brazil. Atônita, fui falar com o professor do curso, Henry Hoenigswald, e disse: "essas línguas estão todas mortas, esses índios não existem mais". Foram Henry Hoenigswald e Terence Kaufman, colega de outro curso e que estava fazendo seu doutorado sobre o Tzeltal, língua maia falada no México, que me abriram os olhos para esse campo de trabalho e para a grande diversidade que aqui havia e não estava sendo estudada. Se embarquei, fervorosa, na canoa da Linguística indígena, devo a eles. Descobri, assim, bem tarde, a existência das línguas e dos povos indígenas brasileiros.

\section{O acaso}

O acaso da descoberta e minha ignorância não eram fatos singulares. Em trabalho feito em co-autoria com Bruna Franchetto, intitulado A concepção dos Linguistas (Franchetto \& Leite, 1986), em que entrevistamos os poucos que então se dedicavam à pesquisa com línguas indígenas, a quem perguntávamos "como chegou ao campo das línguas indígenas?" Quase todos responderam: "foi por acaso". O depoimento mais interessante foi o da colega, que queria se especializar em espanhol, mas não tendo dinheiro para ir para a Espanha, foi para o Paraguai e lá descobriu que o guarani era a língua mais falada. Acabou deixando o espanhol de lado passando a se dedicar à nova língua por ela recém descoberta.

Se foi também um mero acaso a minha descoberta da Linguística e as línguas indígenas brasileiras nos Estados Unidos, foi um outro feliz acaso que me levou a Roberto Cardoso de Oliveira e Luiz de Castro Faria, então chefe do Departamento de Antropologia do Museu Nacional, onde pude iniciar a minha formação em línguas indígenas brasileiras. Num jantar conheci o jovem antropólogo Roberto Cardoso de Oliveira, filósofo por formação e 
que, tal como Lévi-Strauss, procurara outros modos e de pensar o homem e o mundo, introdutor no Brasil do pensamento antropológico inglês e da antropologia estrutural. Foi ele quem me indicou o Museu Nacional, de onde era o coordenador do Setor de Etnologia, o Setor de Linguística, a cargo do renomado J. Mattoso Câmara Júnior, com a finalidade de documentar, descrever e analisar as línguas indígenas brasileiras. Para lá me dirigi na manhã seguinte e lá fiquei até minha aposentadoria.

\section{A Linguística sob a égide da antropologia}

Naquela época a Linguística não era ainda institucionalizada. Somente em 1963 a Linguística tornou-se, por decreto, uma disciplina obrigatória nos cursos de graduação em Letras.

Como mencionado anteriormente havia na Faculdade de Letras da antiga Universidade do Brasil a disciplina isolada, denominada Linguística, lecionada por J. Mattoso Câmara. Advogado de formação e arquiteto Mattoso Camara deixara a arquitetura e o emprego de desenhista, mas continuara a busca da forma, da geometria da linguagem e através dela seus meios e maneiras de modelar os mundos que nos rodeiam. Advogado deixou a advocacia e o formalismo codificado da jurisprudência e partiu à procura das intrincadas leis que regem a misteriosa e quase inacessível faculté $d u$ language, que torna todos os homens iguais. Em Introdução às Línguas Indígenas Brasileiras diz-nos "do ponto de vista do Linguista a área La donna è mobile tem o mesmo interesse e valor, quer cantada por Gigli, quer cantada por mim, porque justamente o que determina a maestria de Gigli são os elementos que estão na parole, ou fala, mas não pertencem à língua" (Mattoso Camara Jr., 1965: 14). Apesar da forte oposição dos prescritivistas, vislumbrava, assim, o início do fim, ao menos teoricamente, das dicotomias valorativas língua rica/língua pobre ou língua culta/ língua popular; língua de civilização/ língua indígena, uma vez que a linguagem humana passou a ser entendida como uma faculdade mental igual para todos, um sexto sentido, como a visão, o olfato, a audição, o tato, o paladar (Fodor, 1983).

Era comum, à época, que o estudo de línguas indígenas fosse domínio dos museus e da antropologia Foi no Museu Paranaense, à convite de Mansur Guérios, que Aryon Dall'Igna Rodrigues iniciou seu trabalho de campo entre os índios Xetá. Darcy Ribeiro era titular da disciplina de Etnografia e Língua Tupi do curso de Ciências Sociais da Faculdade de Letras da Universidade do Brasil. E Mattoso Câmara, encontrou no Museu Nacional, no Departamento de Antropologia, o espaço institucional para desenvolver plenamente seu 
ofício de Linguista. E o fez gratuitamente, recebendo em troca o reconhecimento e a admiração de seus colegas de Departamento. A solicitação feita pelo Museu Nacional para sua transferência da Faculdade de Filosofia, Ciências e Letras para o Museu Nacional foi negada sob a alegação de se tratar de um mero professor de uma disciplina isolada. O Setor de Linguística por ele planejado funciona até hoje no Museu Nacional, abrindo suas portas a quem quiser se especializar na documentação e análise das línguas indígenas brasileiras. E até hoje perdura no Museu Paraense Emílio Goeldi um Setor de Linguística, muito bem aparelhado, sede de várias pesquisas sobre línguas indígenas amazônicas.

\section{As relações entre língua, cultura e visão do mundo}

A visão vigorante da relação entre língua e cultura era expressa nos três níveis de Kroeber: nível inorgânico correspondendo ao mundo físico, o nível orgânico, correspondente ao mundo biológico, e o superorgânico, entendido como o mundo da criação humana, o da cultura e da linguagem. Como, porém, a linguagem funciona na sociedade para a comunicação dos seus membros, a língua depende de toda a cultura pois tem que expressá-la a cada momento. Assim a língua é parte da cultura, mas se destaca do todo e com ele funciona dicotomicamente (Mattoso Câmara Jr.1959: 19-21). Pode-se ver então a forte união e interesse existente entre a Linguística e a antropologia e por que seu locus de preferência eram os museus, onde existia um Setor de Antropologia e seus parceiros, os antropólogos.

Porém a linguagem não se limita a expressar o mundo físico, biológico e super-orgânico. Nem as relações entre linguística e antropologia e linguistas e antropólogos podem se limitar ao fornecimento de ferramentas para que o antropólogo aprenda a língua, muitas vezes não descrita, dos povos que estuda para poder com eles se comunicare. Essa seria uma visão meramente funcional das relações entre linguística e antropologia. Do ponto de vista epistemológico, a questão é bem mais complexa e perdura há muitos séculos: a relação entre linguagem pensamento e realidade ou visão do mundo. As correntes filosóficas que tratam da correlação linguagem, pensamento e realidade se dividem e se entrelaçam. O papel da linguagem no processo de cognição é um dos problemas mais antigos da epistemologia. Algumas correntes consideram a linguagem como um meio de o homem estabelecer contato com a realidade e de expressar o mundo objetivo. A linguagem seria a cópia desse mundo dele retratando os recortes e as idéias. Outros já pensam que a linguagem não é uma cópia da realidade, mas é ela que 
cria subjetivamente o mundo externo ou a realidade. Outros sustentam a hipótese de que todos os homens passaram pela mesma evolução biológica, sendo a imagem do mundo formada no processo de evolução sendo a mesma para todos. A evidência para essa perspectiva é que os mesmos elementos lingüísticos são encontrados em todas as línguas. Assim todas as línguas têm classes morfológicas como substantivo e verbo, nomes designadores de pessoa e nomes que designam objetos, qualificadores, pronomes, e também mecanismos que diferenciam sentenças afirmativas, negativas e interrogativas.

Nessa controvérsia Humboldt adota uma posição moderada. Para ele seria minimizar o estudo da linguagem considerá-la apenas um meio de estabelecer contato com o mundo objetivo. A verdadeira essência das pesquisas em Linguística seria estudar a participação da linguagem na confecção das idéias. Nessa perspectiva a questão de a linguagem refletir, ou não, a realidade se torna mais complexa, uma vez que envolve a dialética de fatores objetivos e subjetivos na cognição. Para Jost Trier, Leo Weisberger e outros, o problema se simplifica: a língua não reflete a realidade, não há fatores objetivos e subjetivos. A linguagem simplesmente cria subjetivamente a realidade ou a visão do mundo. ${ }^{1}$

Para os antropólogos tais perguntas são de grande relevância. O mister do antropólogo é depreender a visão do mundo da sociedade que investiga, suas crenças, valores que lhes são subjacentes. Enfim o ofício do antropólogo é captar e traduzir como pensa e sente a sociedade que estuda. Se a língua reflete a visão do mundo, essa seria a chave que o antropólogo teria para traduzir esse mundo. Para tal ele tem de saber a língua falada pela sociedade investigada, pois é a linguagem que lhe fornece as evidências para consubstanciar o entendimento das categorias que codificam a cognição e classificação do mundo.

\section{Estruturalismo e relativismo: a hipótese Sapir-Whorf e a etnociência}

É bem conhecida dos Linguistas a hipótese do relativismo linguístico formulada por Sapir a qual pode ser sumariada do seguinte modo: a cada língua é inerente uma visão específica do mundo. A língua que uma determinada comunidade fala e com que pensa organiza a experiência e assim molda o mundo e a realidade social dessa comunidade. A exegese da obra de Sapir não nos autoriza a dizer que a língua cria a realidade. Sua tese é que a linguagem é socialmente condicionada e influencia o modo por que uma comunidade apreende a realidade. Seria ilusório imaginar que alguém se 
ajuste à realidade sem o auxílio da língua e que a língua seja meramente um meio ocasional de resolver problemas específicos de comunicação e raciocínio. Para Sapir, o fato inconcusso é que o "mundo real" se constrói inconscientemente, em grande parte, na base de hábitos linguísticos do grupo. Mais ainda, segundo sua concepção não haveria duas línguas que fossem bastante semelhantes para que se possa dizer que representam a mesma realidade social. Daí se segue que as diversas sociedades humanas são mundos distintos, não apenas um mundo com rótulos diversos.

Whorf radicaliza a proposta de Sapir que propunha, como Humboldt, uma relação dialética entre o mundo objetivo ou social e o reflexo deste mundo na linguagem. Whorf, por seu lado, se aproxima de Trier e Weisberger ao dizer que o mundo se apresenta num fluxo caleidoscópio de impressões que devem ser, em parte, organizadas pelo sistema lingüístico de nossas mentes.

No livro de Adam Schaff, Linguagem e cognição, se encontra uma apresentação didática do histórico da questão, suas possibilidades de verificação empírica e contra-argumentações. Ressalta também a potencialidade dos trabalhos de EtnoLinguística de fornecer evidências a favor ou contra algumas hipóteses epistemológicas.

A concepção de que o vocabulário estruturado em campos semânticos retrata o recorte da realidade deu origem, em Antropologia, a uma linha de pesquisa chamada etnociência. O artigo de Conklin sobre a classificação de cores em Hanunoo, o de Frake sobre o diagnóstico de doenças entre os Subanun of Mindanao e vários artigos de Lounsbury e Goodenough procuram demonstrar como a taxionomia Linguística aliada à detecção dos componentes semânticos dos itens vocabulares traduzem uma visão e apreensão do mundo própria a cada cultura. De acordo com essa corrente, o único meio de chegar-se à essência de uma cultura seria estabelecer os seus sistemas classificatórios semânticos, consubstanciados no vocabulário e na gramática de uma língua.

A hipótese do relativismo foi adotada por uma corrente extremada do estruturalismo linguístico norte-americano. Os estudos sobre as línguas indígenas se intensificaram sob essa bandeira e um dos objetivos era descobrir novas estruturas Linguísticas e demonstrar o quanto elas se diferenciavam das chamadas línguas de civilização. Essa concepção chegou a um tal grau de radicalismo que se aconselhava a evitar, nas descrições gramaticais a nomenclatura tradicional como substantivo, verbo, adjetivo, singular, plural, pronome, preposição, possessivo, imperativo, oração ou sentença. Os morfemas e as raízes deveriam ser numeradas, ao invés de traduzidas e rotuladas. Cada língua era um mundo em si e por si, intraduzível em outra, pois cada uma encerrava uma concepção de realidade, não tendo, pois, cor- 
respondente em outra língua porque cada uma encerraria uma concepção diferente da realidade.

A negação dos aspectos universais do fenômeno lingüístico foi duramente criticada pelos seguidores do paradigma que sucedeu o estruturalismo behaviorista: a gramática gerativa de inspiração cartesiana.

\section{A Linguística como fornecedora de um método}

Na área das Ciências Humanas onde mais ecoou a possibilidade de colaboração entre dois campos de conhecimento foi, sem dúvida, entre a Linguística e a Antropologia. Relembrando o passado, não seria exagero dizer que a Linguística ganhou entre nós fama e prestígio e despertou maior interesse nos meios intelectuais não pelo conhecimento das estruturas Linguísticas em si, mas sim, pela sua possibilidade de oferecer um método de trabalho rigoroso, passível de ser utilizado por outras áreas.

Refiro-me especificamente à grande aceitação dos trabalhos de Claude Lévi-Strauss e à voga do estruturalismo. É celebre entre os cientistas sociais e leitura obrigatória dos intelectuais da época, a colocação feita no artigo "A análise estrutural em Linguística e antropologia" de que "no conjunto das ciências sociais, ao qual indubitavelmente pertence, a Linguística ocupa um lugar excepcional; ela não só é uma ciência social como as outras, mas a que, de há muito, realizou os maiores progressos; a única, sem dúvida, que pode reinvidicar o nome de ciência e que chegou, ao mesmo tempo, a formular um método positivo e a conhecer a natureza dos fatos submetidos à sua análise" (Lévi-Strauss, 1967: 45-70).

Também se tornou lugar comum a comparação que fez entre o papel desempenhado pela física nuclear entre as ciências exatas e a Linguística, especificamente a fonologia, entre as ciências humanas. Como diz Lévi-Strauss (idem: 47) no já citado artigo: "A fonologia não pode deixar de desempenhar perante as ciências sociais, o mesmo papel renovador que a física nuclear, por exemplo, desempenhou no conjunto das ciências exatas".

Daí o entusiasmo pela metodologia Linguística, ciência que compara à física, ciência das ciências, que dividira o átomo em seus elementos constitutivos - nêutrons, prótons, elétrons - e a Linguística que decompusera o fonema, sua unidade mínima, em traços constitutivos articulatórios e acústicos mínimos. Pode-se dizer que a Linguística se popularizou no Brasil através da antropologia e de Lévi-Strauss autor cult da década dos anos 60 e de seu livro Antropologia Estrutural, leitura indispensável dos intelectuais da época.

Que metodologia é essa que alçou a fonologia a esse patamar? 


\section{As concepções estruturalistas de fonema}

Duas concepções de fonema, segmento sonoro mínimo que constitui a representação do contínuo da fala, vigoraram no modelo estruturalista. Uma, que caracteriza o modelo estruturalista norte americano trazido para o Brasil pelo Summer Institute of Linguistics (SIL), hoje denominado Instituto Internacional de Linguística, define o fonema como uma classe de sons em distribuição complementar ou em variação livre, que contrasta com outra classe de sons. A substituição de uma classe por outra acarreta mudança de sentido, como em mata: nata: lata: pata: bata: data: gata: chata. Nesta corrente o fonema é a unidade mínima, que se poderia comparar ao átomo da física.

Porém é uma outra concepção de fonema é que aproxima a Linguística da física. Trata-se da corrente que teve origem no Círculo Linguístico de Praga, do qual fazia parte Roman Jakobson, e que define o fonema como um feixe de traços distintivos.

A definição de esposada por Roman Jacobson, professor de Mattoso Câmara e de Lévi-Strauss em curso feito em Nova Iorque em 1942, é a que permite essa comparação. O fonema é o átomo, o qual é decomposto em seus traços constitutivos de natureza acústico-fonética, esses, sim, os elementos que o constituem a unidade mínima, comparáveis aos elementos mínimos que constituem o átomo, e que diferenciam um fonema do outro. Os traços constitutivos dos fonemas podem ser positivos ou negativos. Assim o fonema / p / e / b / se distinguem por ser o $b$ [+sonoro] e $p$ [-sonoro], ambos compartilhando o traço [+labial] e [-contínuo]. Assim é o traço [sonoro] que opõe os dois segmentos e os tornam segmentos contrastivos. A noção de oposição e contraste é fundamental e básica para a distinção entre as unidades fonológicas.

\section{A aplicação da metodologia Linguística na antropologia}

Foi a noção de oposição e a de traços distintivos que Lévi-Strauss levou para a antropologia e aplicou com sucesso preliminarmente na análise de variantes de mitos e no estudo de sistemas de parentesco. Em seu artigo "A estrutura dos mitos" (Lévi-Strauss, 1967: 237-265), seguindo uma técnica semelhante á usada para a depreensão de fonemas, estabelece uma unidade mínima de análise o mitema paralela palavra calcada à base de fonema. E, no sistema de parentesco, ainda com base na noção de oposição própria da Linguística, reformula a teoria existente sobre unidades nucleares de um sistema opositivo nas atitudes de relacionamento entre dos pares pai/filho; irmão/irmã; marido/mulher; tio materno/filho da irmã. Limitamo-nos aqui 
às primeiras incursões de Lévi-Strauss no uso da metodologia Linguística. Sua obra é conhecida pelo público brasileiro, não tendo tido a mesma repercussão na antropologia norte-americana. Livros, como O cru e o cozido (Lévi-Strauss 1964), cujo título que em si já contém a noção de oposição, O totemismo hoje, O pensamento selvagem, ultrapassaram o mundo antropológico e fizeram parte do mundo da Literatura e da Filosofia.

Vale a pena salientar que entre os antropólogos brasileiros as idéias de Lévi-Strauss não se restringiram à discussão acadêmica ou a exposições em sala de aula ou conferências.

Elas foram utilizadas para a interpretação de dados antropológicos, oriundos de pesquisa de campo entre etnias indígenas brasileiras. Parte desses trabalhos foi reunida em Mito e linguagem social. Assim é que Roberto Cardoso de Oliveira no artigo "Totemismo Tukuna?" invoca entre o Tukuna do alto Solimões uma ordem totêmica consubstanciada nos epônimos clânicos transformados em signos que codificariam a ordem social e que viriam a constituir um plano de referência eficaz para o comportamento social. Data da mesma época o artigo de Roberto Augusto da Matta em que, depreendendo os mitemas do mito do fogo e do mito da origem do homem branco entre os Timbira, mostra como eles estão relacionados do ponto de vista estrutural, mantendo entre si relações inversas e simétricas. Nessa mesma perspectiva Roque de Barros Laraya, em "O sol e a lua na mitologia xinguana", analisa três versões de mitos da origem, uma Bakairi, outra Kalapalo e outra Kamaiurá, demonstrando que as diferenças são apenas aparentes. Os elementos básicos são em essência os mesmos nas três versões, isto é, não estão em oposição são apenas variantes em distribuição complementar, que servem como um modelo em termos ideais para a ação social. Seguindo o mesmo procedimento, Julio César Melatti, em "O mito e o xamã", estabelecendo os mitemas de biografias de xamãs e os mitemas do mito Krahó que explica as origens dos poderes de curar, mostra que essas biografias revivem o mito.

\section{O papel da Linguística no Museu Nacional}

O diálogo dos Linguistas e antropólogos foi intenso no Museu Nacional. Mattoso deu cursos de Linguística para os antropólogos, tendo, como alunos, Roberto Cardoso de Oliveira, Luiz de Castro Faria, Roberto Augusto da Matta, Roque Laraia. Esse curso foi gravado e publicado pelo Museu Nacional com o título Introdução às línguas Indígenas Brasileiras com suplemento sobre a Técnica da Pesquisa por Sarah Gudschisnky, do Summer Institute of Linguistics. É o primeiro e único livro que se tem até hoje de introdução às línguas 
indígenas brasileiras, a sua diversidade e a metodologia de como registrá-las e analisá-las. O Summer Institute of Linguistics foi uma instituição que também desempenhou o seu papel no Museu Nacional, através de convênio, competindo-lhes registrar e descrever as línguas indígenas. Descrever consistia basicamente em depreender os fonemas, (os sons que contrastavam, o chamado nível fonético-fonológico), identificar os morfemas que formavam as palavras - morfologia - e como as palavras se arrumavam em frases ou sentenças - o nível sintático: sentenças afirmativas, interrogativas, negativas, causativas, interativas, principais, dependentes, imperativas etc. e fazer um vocabulário em que constavam as palavras básicas, nucleares da língua. A finalidade última era classificar geneticamente as línguas documentadas. Havia, e era obrigatório preencher e arquivar no Setor de Linguística do Museu Nacional, o Formulário dos vocabulários padrões para estudos comparativos preliminares nas línguas indígenas brasileiras.

A relação SIL/MN era ambígua e conflituosa, às vezes beligerante, pois tratava-se de uma instituição religiosa que tinha como finalidade última traduzir a bíblia na língua indígena para convertê-los, substituindo-se assim os mitos e práticas indígenas.

O modelo aplicado era o do mentor máximo do SIL Kenneth Pike: uma rápida identificação fonética dos sons, para que se pudesse reduzir a fonética em fonêmica (pedra de toque da Linguística da época), a fim de se poder escrever a língua alfabeticamente. Tanto assim que o livro de Kenneth Pike, Phonemics, tem como subtítulo uma técnica para reduzir a língua à escrita. Só então poderia se começar o processo de alfabetização, dito bilíngue, o primeiro passo necessário para a tradução da Bíblia na língua indígena. E, em troca de uma língua escrita e da tradução da bíblia em sua língua nativa o que lhes permitiria ler o Livro Sagrado, os índios deveriam abrir mão de suas crenças, de seus costumes e de seus mitos.

\section{O desencontro entre a concepção de linguagem dos linguistas e a dos tapirapé}

Como já se disse fazer Linguística implicava fazer uma descrição fonológica, uma morfológica e uma descrição sintática, talvez um dicionário ou uma lista lexical. Cumpria, assim, determinar para cada língua os fonemas (os sons contrastivos), os morfemas (as unidades mínimas com significação) e tipos de frases (negativas, interrogativas, principais, subordinadas, imperativas dubitativas), colher mitos, relatos, etc. A recolha dos mitos, no entanto, não tinha a função ser uma expressão da cosmovisão, nem eram os mitos tratados 
como um dos gêneros de fala. Os mitos eram necessários para complementar e ilustrar as estruturas morfológicas e sintáticas. A gramática daí resultante era baseada na recolha de frases isoladas. Nos mitos encontraríamos outros tipos de construção e o encadeamento das sentenças. Eram como se dizia, exemplos contextualizados de construções mais amplas e não, frases isoladas, como as que compunham o Formulário dos vocabulários padrões para estudos comparativos preliminares das línguas indígenas brasileiras. Esse Formulário tinha como finalidade registrar o vocabulário básico, constante das palavras nucleares de uma língua, como partes do corpo (pé, mão, cabeça, pescoço, joelho, perna, braço, boca, nariz) órgão como fígado, coração, pulmão, alguns animais (macaco, jacaré, onça, cachorro, cobra, anta) verbos como ver, cheirar, ouvir, comer, beber, morrer, nascer, cair dormir falar, lua, sol, dia noite, água, palavras consideradas básicas em qualquer língua e menos passíveis de serem empréstimos e algumas frases de tipo afirmativo, como a criança está vomitando; ele está sentado perto do fogo, a árvore está queimando; interrogativas, Quem está vindo? Onde vai cavar? Quando vai caçar"; negativas, Ele não comeu hoje, ele não matou o passarinho, Não mate, não. São frases descontextualizadas e soltas, algumas que retratam ações inimagináveis no contexto indígena como ele está puxando o rabo do macaco, passando, assim, desordenadamente do mundo real e próximo para o mundo não real e tido como impossível. Os exemplos encontrados nos mitos e relatos ultrapassavam os obtidos apenas na linguagem cotidiana e são contextualizados culturalmente e aceitos como verdade. Assim era possível ampliar linguisticamente os dados e sua análise gramatical.

Um exemplo do desencontro entre a concepção da linguagem dos tapirapé (família tupi-guarani) e a dos Linguistas se verificou na primeira etapa do processo de alfabetização em tapirapé. O professor primeiro mostrou uma figura de um homem de costas andando num caminho com uma espingarda e uma foice. Depois escreveu no quadro negro a frase: xeropy aa kape "meu pai foi à roça" e todos os alunos recusaram a sentença que, numa perspectiva gramatical, está correta, mas sem as informações necessárias para sua aceitação cultural. Em primeiro lugar a figura exibida mostrava um homem tapirapé. Os alunos imediatamente começaram a fazer perguntas: pai de quem? Não poderia ser o pai do professor que não é tapirapé. Fazer o que na roça? Foi sozinho? Geralmente é uma família ou um grupo que vai à roça. Outro exemplo foi minha tentativa de testar a sentença Marevira aa kape "Marevira foi à roça" em comparação a kape ia Marevira, a qual todos responderam que estava tudo errado. Gramaticalmente a sentenças estavam certas. Porém, o seu valor de verdade era falso porque não retratavam um fato acontecido, uma vez que Marevira não havia ido à roça tendo ficado em casa. 
Os trabalhos linguísticos não levavam em conta as funções da linguagem nas línguas indígenas nem o seu uso. Desconheço trabalhos de Linguistas que se fale da "etiqueta" Linguística o que e deve dizer quando se entra numa casa, ou quando se sai, quando se pode falar, quando não se de falar, com quem não se pode falar. Um trabalho exemplar, que foge a essa regra é o de Keith Basso sobre o silêncio em Navaho. E mais ainda, nada existia sobre as diversas modalidades de fala. O único trabalho que conheço até hoje em que se encontra uma descrição Linguística e uso da linguagem e gêneros de fala é a tese de doutorado de Bruna Franchetto, defendida em 1986, no Programa de Pós-Graduação em Antropologia Social do Museu Nacional.

\section{As relações felizes entre a Linguistas e antropólogos}

A relação entre Linguistas e antropólogos no Museu Nacional era intensa nas décadas dos anos 60 do século passado. Os Linguistas apresentavam comunicações nas reuniões bianuais da ABA, davam cursos de Linguistas para os etnólogos para que pudessem aprender a língua do grupo que iriam estudar. Caso houvesse material sobre a língua do grupo, poderiam aprender a terminologia e lê-lo, caso não houvesse cumpriria fazer a descrição da língua. Essa possibilidade de o etnólogo aprender a língua do pesquisado foi um traço singularizava a etnologia do Museu Nacional. Tânia Stolze de Lima, Carlos Fausto, Marco Antonio Gonçalves. Vanessa Lea, Aparecida Villaça foram alguns dos que se submeteram ao ritual sofrido, com horas e horas de exercícios de fonética, morfologia e tipos de frases, mas que muito lhes valeu em seu relacionamento com o grupo por poder falar sua língua e para entendimento das categorias e pensamento nativos, uma vez os mitos eram registrados na língua do grupo. Os linguistas assistiam às palestras dos antropólogos que nos visitavam e vice-versa. O antigo auditório do Museu ficou lotado na conferência de Roman Jakobson, amigo de Mattoso Câmara, de quem foi professor no Curso feito nos Estados Unidos, do qual foi aluno também Claude Lévi-Strauss.

A pós-graduação em Linguística teve com primeira sede o Museu Nacional. Porém em 1970 passou para a Faculdade de Letras da UFRJ e a relação entre Linguistas e antropólogos começou a fenecer. Outras Universidades, como Universidade Estadual de Campinas, Federal de Goiás, Universidade de Brasília, a Universidade Federal de Pernambuco, Universidade Federal do Pará passaram a formar Linguistas, com pouco ou nenhum convívio com a Antropologia. Fundou-se a Associação Brasileira de Linguística (ABRALIN) 
e a Associação Nacional de Pós-Graduação e Pesquisa em Letras e Linguística (ANPOLL). Os linguistas passaram a ter seus espaços próprios de interlocução e apresentação de trabalhos.

A morte do estruturalismo e o advento da gramática gerativa foi um fator decisivo para o afastamento entres os dois campos de conhecimento.

\section{Um novo paradigma: a gramática gerativa}

O advento da Gramática Gerativa de Noam Chomsky que concebe a Linguística como uma ciência da mente, retira a Linguística do campo da Sociologia e da Antropologia, passa a ter um maior diálogo com a Psicologia e Neurologia.

Na conferência de Eric Lennerberg sobre Fundamentos Biológicos da Linguagem, antropólogos, botânicos, zoólogos não encontravam lugar para sentar. Já o curso dado por Joel Sherzer sobre Etnografia da Fala teve, como alunos, antropólogos, mas os Linguistas não compareceram, uma vez que tinha, como foco, o uso contextualizado da linguagem.

A distância entre os dois campos começa a se aprofundar não só com a mudança da Linguística para as Faculdades de Letras, mas também com o novo paradigma proposto por Noam Chomsky, que sucede ao estruturalismo, a gramática gerativa, a qual retira a Linguística da área das ciências sociais e a inscreve na área das novas ciências da mente (cf Gardner 1985).

A comparação feita por John Lyons (Lyons 1982: 17-21) das definições de Sapir e Bloch \& Trager e Noam Chomsky retrata a dimensão da mudança. Sapir (1921: 8) definiu a linguagem como "um todo puramente humano e não instintivo de se comunicarem ideias, emoções e desejos por meio de símbolos voluntariamente produzidos; Bloch e Trager (1942:5) descrevem a língua "como um sistema de símbolos vocais arbitrários por meio do qual um grupo social coopera". E Noam Chosmky. no revolucionário Syntactic Structures (1957: 13) considera "uma lingua (gem) como um conjunto (finito ou infinito) de sentenças cada uma finita em comprimento e construída a partir de um conjunto finito de elementos". A palavra social não é mencionada, muito menos comunicação ou interação.

O modelo gerativo e o livro Syntactic Structures, cuja primeira edição é de 1957 marca a entrada em cena de um novo modo de pensar e fazer Linguística dada à mudança radical uma vez que o foco deixava de ser as línguas em si e por si e a ser a caracterização da faculdade humana da linguagem. 


\section{Uma nova Ciência da Mente}

Chomsky, no prefácio a Knowledge of Language: Its Nature, Origin and Use, identifica como o primeiro problema referente ao conhecimento a ser explicado é como sabemos tanto dado que as evidências que temos são limitadas. A esse dá o nome de Problema de Platão. Essa questão, como Chomsky assinala, já fora expressa por Bertrand Russell em seu último trabalho ao indagar a seguinte questão: Como é que os seres humanos têm a capacidade de saber tanto quanto sabem uma vez que seus contactos com o mundo são breves, pessoais e limitados. Em termos linguísticos, as evidências advêm da interpretação de construções como Pedro deu um livro para ele, ele não pode ter como seu referente Pedro? E como é em Pedro perdeu o relógio que ele havia comprado há poucos dias, ele pode ter como referente Pedro? A definição clássica que temos em nossas gramáticas de que o pronome é a palavra que substitui o nome não dá conta desse fato. Qual a origem desse conhecimento? O foco do estudo em Linguística muda do uso e comportamento externalizados para a caracterização do sistema de conhecimento e princípios subjacentes ao uso e entendimento da linguagem externalizada para a caracterização dos princípios inatos e biologicamente determinados, que constituem um componente da mente humana, especificamente, a faculdade de linguagem ou Gramática Universal. (Chomsky 1986:15-50).

A agenda da teoria gerativa para responder as questões que emergem da mudança de foco do comportamento ou dos produtos do comportamento para estados da mente/cérebro que fazem parte do comportamento implica na resposta são: i) o que constitui conhecimento da linguagem; ii) como o conhecimento da linguagem é adquirido; iii) como o conhecimento da linguagem é posto em uso.

Embora o gestor desse modo de conceber a Linguística tenha expresso claramente que A gramática gerativa é um tópico que se escolhe estudar ou não (Chomsky, 1986:4), o advento da gramática gerativa motivou nos meios linguísticos uma cisão ou uma guerra entre os gerativistas e os não gerativistas. Aqueles que optaram por seguir a nova corrente partiam como os cruzados medievais em luta contra os incréus e conversão de novos adeptos. O tema, a meu ver, é digno de uma análise antropológica. A figura de Noam Chomsky tornou-se mítica, pelos pressupostos da nova concepção de linguagem/língua, a se que somava atitudes políticas de vanguarda, liderando passeatas contra s governo norte-americano por sua interferência em outros países, sendo arrastado por policiais para os camburões de presos. Em sua vinda ao Brasil, fez questão de visitar uma comunidade do morro, dando entrevista na rádio local e também de conhecer e conversar com os Linguis- 
tas do Museu Paraense Emílio Goeldi sobre as pesquisas com as línguas indígenas minoritárias, prestigiando, assim, os linguistas que não se limitam à descrição das línguas indígenas, enquanto documentação de uma língua desconhecida, desempenhando também o papel de guardiães da integridade física, Linguística e cultural dessas etnias sobreviventes em nosso País.

Que papel vêm desempenhado os antropólogos na chamada revolução cognitiva ou novas ciências da mente?

\section{A mente primitiva}

Lévy-Bruhl (1912) se notabilizou entre os estudiosos da mente humana por ser o primeiro a propor uma reflexão sobre as diferenças entre a mentalidade primitiva e a mentalidade moderna. A mente primitiva seria mística e pré-lógica e a segunda racional e lógica. A dicotomia semelhante foi aplicada às línguas aqui faladas à época da conquista, de conceituação essa derivada da inexistência de um sistema de escrita, de terem uma ordem sintagmática livre sem a devida marcação de casos nominativo e acusativo para diferenciarem o sujeito e o objeto, como o latim. Haveria, assim, as línguas lógicas passíveis de serem analisadas em termos gramaticais de sujeito, verbo, objeto, quer por marcação de caso como o latim e o grego quer pela ordem dos sintagmas nominais, como em português, inglês, francês, chamadas línguas de civilização e línguas primitivas, sem escrita, com ordens sintagmáticas variáveis, sem marcação de caso. A língua dos Tupinambá, com que os conquistadores tiveram seu primeiro contato, não têm uma marcação de caso, nem uma ordem fixa que distinga o sujeito do objeto. Assim frases como "meu pai matou a onça, a onça matou meu pai" podem significar tanto "meu pai morreu" ou que "a onça foi morta". Cumpre aqui ressaltar que a Gramática a língua mais usada na costa do Brasil do Pe José de Anchieta já observa esse fato, sem emitir qualquer juízo de valor.

Nos últimos anos de sua vida, Lévy-Bruhl renuncia à sua proposta original em suas anotações publicadas após sua morte. Declara que nunca conseguiu comprová-la nem defendê-la e num rasgo de idoneidade acadêmica declara: "Não há uma mentalidade primitiva distinguível da outra" (Cazeneuve, 1972:86-87, apud Gardner, 1985:224).

Roberto Cardoso de Oliveira, no capitulo final ao ensaio Razão e Afetividade: o pensamento de Lévy-Bruhl, considera que

[...] L-B ${ }^{2}$ se não inovou na temática, certamente inovou no método. Um método, é verdade, que teria servido mais para encaminhar as questões filosóficas dis- 
persas na atmosfera filosófica de seu tempo, ou por ele mesmo formuladas, do que implementar algo novo na metodologia etnológica. L-B, compulsivamente contrário à especulação, como demonstra toda sua obsessão pelo dado especulou à sua maneira. [...] Todavia, se esse" pensamento primitivo" ou dos"selvagens" foi por ele revelado como sendo um produto entre a razão e a afetividade, já seu próprio pensamento jamais deixou de se guiar pelo racionalismo inerente a sua formação.[...].L-B não sucumbiu à ilusão racionalista ( a de um intelectualismo puro), sabendo trazer para o campo de suas investigações a questão da afetividade e esclarecendo o lugar por ela ocupado nas representações observáveis em mundos outros que o da intelectualidade européia" (Cardoso de Oliveira, 1991:160-161).

\section{A natureza dos dados}

O problema central que a Linguística gerativa formulou, na busca para a apreensão da gramática internalizada pelos falantes de uma língua, é a natureza dos dados. Uma gramática de uma língua deve gerar só e somente só as formas consideradas gramaticais pelo falante nativo. O modelo linguístico só deve conter regras que são encontradas nas línguas conhecidas até hoje e prever a inexistência de outras formas. Por exemplo, podemos fazer o plural de uma palavra acrescentando-se um morfema de plural ou o feminino, quer seja um sufixo, um prefixo ou um infixo. Porém, até hoje não se encontrou uma língua cuja regra seja a inversão de toda a sequência de segmentos mínimos da palavras, isto é, formalizando, o plural de uma palavra não pode ser abcdef + pl. $\rightarrow$ fedcba.

O lema inicial da gramática gerativa foi: a weak theory and strong claims. O modelo formal proposto deve poder gerar sentenças do tipo a) O menino caiu ou b) O menino que correu atrás do cachorro que pegou o gato que matou o rato caiu. Mas não deverá gerar sentenças do tipo c) O menino, o cachorro, o gato, o rato correu atrás, pegou, mato, caiu. Tratava-se então de formular um modelo formal que permitisse gerar apenas as sentenças gramaticais (a) e (b) e não gerasse sentenças agramaticais como (c).

Já em Antropologia é difícil formular qual a natureza dos dados que leve a conhecimento internalizado pelos componentes da sociedade em estudo. Gravar mitos? Filmar os cerimoniais? Observar e anotar os comportamentos considerados corretos? Fazer perguntas diretas sobre os modos de agir? Qual a metodologia da Antropologia além da observação participante e das anotações em um diário? Qual a linguagem escolhida que expresse as relações do sistema de parentesco, por exemplo? Uma árvore genealógica é suficiente? Qual a representação que seria uma adequada? 


\section{De volta à etnociência}

Na seção Estruturalismo, gerativismo: a hipótese de Sapir-Whorf e a etnociência mostrou-se que a decomposição do léxico em seus componentes mínimos de uma dada área semântica, como, por exemplo, o parentesco, talvez resultasse em uma análise mais objetiva e mais próxima à representação internalizada pelo usuário. Também forneceria, assim, uma metodologia mais objetiva e, digamos, "científica".

Ocorre que na Linguística o estabelecimento dos traços semânticos dos itens lexicais que são classes abertas, pois cada introdução de um novo item exige uma revisão das oposições de significado não se tem até hoje um sistema de traços, para outros componentes da gramática como a fonologia ou morfologia, que são sistemas fechados foi possível em pouco tempo se constituir o arsenal de seus traços constitutivos que ocasionam a diferença de significado. Com relação à sintaxe, a neurolinguística vem fornecendo evidências concretas para a proposta de diferentes representações para tipos diferentes de construções, por meio de reações diferenciadas, detectáveis em eletroencefalogramas (Franca, Lemle, Cagy et alii, 2004).

Cumpre salientar que a teoria das representações propostas pela gramática gerativa, para desespero de seus seguidores, vem sendo ajustada e modificada frequentemente desde a primeira incursão no revolucionário Syntactic Structures (1957) até A minimalist program (1995). Como o último título diz, não se trata da apresentação de um novo modelo teórico, mas sim, de um programa de investigação.

Voltando ao começo, posso dizer que aquela adolescente cujo mundo se limitava ao Posto 4 da Praia de Copacabana viajou, em companhia de seus colegas antropólogos por outros mundos distantes geograficamente, como o dos Pirahã retratado por Marco Antonio Gonçalves, cuja complexa cosmologia contrasta com a rusticidade de sua vida material, o dos Araweté, estudados por Eduardo Batalha Viveiros de Castro, só comparável ao relato da Retirada da Laguna de Taunay, o dos Tapirapé, minha segunda identidade, cuja língua estudei e onde tenho até hoje amigos além de irmãos, irmãs, cunhados, cunhadas, sobrinhos e netos. Outros bem próximos, em meu próprio território, mas que nem sonhava a existência, como os moradores de em edifício do posto 5 , que deixaram uma casa em rua tranquila e arborizada do subúrbio por um apartamento de quarto e sala em rua barulhenta e poluída de Copacabana, descritos por Gilberto Velho em A Utopia Urbana e as Lan Houses que estão por todo o Rio de Janeiro que só fui conhecer recentemente, como membro da banca de doutorado de Vanessa Andrade Pessoa. A vocês todos, pelo redimensionamento de minha visão do mundo, o meu muito obrigada. 


\section{Notas}

${ }^{1}$ Para um aprofundamento da questão veja-se Adam Schaff, 1973, cap. I Linguistics: from Herder to the Theory of Linguistic Fields.

${ }^{2}$ Sigla usada pelo autor para se referir a Lévy-Bruhl.

\section{Referências bibliográficas}

ANCHIETA, Pe. José. Arte de grammatica da lingoa mais usada na costa do Brasil. Salvador: Universidade Federal da Bahia, 1980. Edição fac-similada de 1595.

BASSO, Keith. 1970. "To give up on words": silence in Western Apache Culture. New Mexico: Southwestern Journal of Anthropology, vol, $26 \mathrm{n}^{\circ}$ 3: 213-330.

BLOCH, Bernard \& TRAGER, George L. 1942. Outline of Linguistic Analysis. Linguistic Society of America/Waverly Press.

CARDOSO de OLIVEIRA, Roberto. 1970. Totemismo Tukuna? Mito e linguagem social. Rio de Janeiro: Tempo Brasileiro. pp. 52-64.

- 1991. Razão e Afetividade: o pensamento de Lucien Lévy-Bruhl. Campinas, São Paulo: CLE-UNICAMP.

CHOMSKY, Noam. 1957. Syntactic Structures. The Hague: Mouton \& Co. 1986. Knowledge of language: its nature, origin and use. New York: PRAEGER. - 1995. The minimalist program. Cambridge, Mass.: The MIT Press.

CONKLIN, H.C. 1955. Hanunoo color categories. Southwestern Journal of Anthropology 11(4):339-142.

DAMATTA, Roberto Augusto. 1970. Mito e anti-mito entre os Timbira. Mito e lin- guagem social. Rio de Janeiro: Tempo Brasileiro. pp. 31-77.

FODOR, Jerry A. 1986. La modularidad de la mente. Tradução do o inglês The modularity of mind por José Eugenio Garcia Albea. Madrid: Ediciones Morata.

FRAKE, Charles. 1964. The diagnosis of disease among the Subanun of Mindanao. In: Dell Hymes (ed.) Language in Culture and Society. New York: Harper \& Row.pp.193-211.

FRANCA, Aniela A., LEMLE, Miriam, CAGY, Pedro Constant et alii. 2004. Discriminating among different types of verbcomplement merge in Brazilian Portuguese: an ERP study of morphosyntactic sub-processes. Journal of Neurolinguistics 17: 425-437.

FRANCHETTO, Bruna. 1986. Falar Kuikuro: estudo etnolingüístico de um grupo Karibe do Alto Xingu. Tese de Doutorado. Programa de Pós-Graduação em Antropologia Social. Rio de Janeiro: Museu Nacional. Universidade Federal do Rio de Janeiro.

_ • e LEITE, Yonne. 1983. A concepção dos Linguistas. Cadernos de Estudos Lingüísticos: 4: 15-30, Campinas:Unicamp. GARDNER, Howard. 1985. The mind's new science: a history of the cognitive 
revolution. New York: Basic Books Inc. Publishers.

GONÇALVES, Marco Antonio Teixeira.1988.

Nomes e Cosmos: uma descrição da sociedade e cosmologia Mura-Pirahã. Dissertação de Mestrado. Programa de Pós-Graduação em Antropologia Social. Rio de Janeiro: Museu Nacional. Universidade Federal do Rio de Janeiro.

LARAIA, Roque de Barros. 1970. O sol e a lua na mitologia xinguana. Mito e linguagem social. Rio de Janeiro: Tempo Brasileiro. pp. 77-106.

LENNEBERG, Eric. 1970. Fundamentos biológicos da linguagem. Publicações Avulsas do Museu Nacional, 53.

LÉVI-STRAUSS, Claude. 1962a. Le Totémisme aujourd'hui. Paris: Plon. - 1962b. La pensée Sauvage. Paris: Plon . 1964. Le cru et le cuit. Paris: Librairie Plon.

- 1967. Antropologia Estrutural. Tradução de Chaim Samuel Katz e Eginardo Pires do original francês Anthropologie structurale. Paris: Librarie Plon (1958). Rio de Janeiro: Tempo Brasileiro.

LÉVY-BRUHL. 1912. Les fonctions mentales dans les societés inférieures. Paris:Librairie Felix Alcan.

LYONS, John. 1982. Língua(gem) e Linguística. Tradução do inglês por Matilda Winkler e Clarisse Sieckenius de Souza Rio de Janeiro: Zahar Editores. MATTOSO CÂMARA JR., Joaquim. 1959. Princípios de Linguística geral. $3^{\mathrm{a}}$. Rdição. Rio de Janeiro: Livraria Acadêmica. - 1965. Introdução às Línguas Indígenas Brasileiras. Com suplemento sobre A Técnica da Pesquisa por Sarah Gudschinsky do Summer Institute of Linguistics. Rio de Janeiro: Museu Nacional. MELATTI, Júlio Cézar. 1970. O mito e o xamã. Mito e Linguagem Social. Rio de Janeiro: Tempo Brasileiro. pp. 65-76. PESSOA, Vanessa Andrade. 2008. Na Lan House, "porque jogar sozinho não tem graça": estudo das redes sociais juvenis on-e off line. Tese de Doutorado. Programa de Pós-Graduação em Antropologia Social. Rio de Janeiro: Museu Nacional. Universidade Federal do Rio de Janeiro.

PIKE, Kenneth. 1947. Phonemics: a technique for reducing languages to writing. Ann Arbor: University of Michigan Press.

SAPIR, Edward. 1929 Language. New York Harcourt\& Brace.

- 1951. The Status of Linguistics as a Science. In David G. Mandelbaum (ed.) Selected Writings of Edward Sapir in Language, Culture and Society. Berkeley University of California Press. pp 160-166. SCHAFF, Adam. 1973. Language and Cognition. Introduction by Noam Chomsky. Edited by Robert S. Cohen. Based on a translation vy Olgierd Wojtasiewicz. New York: McGraw Hill Book Company. VELHO, Gilberto Cardoso Alves. 1975. A utopia urbana: um estudo de antropologia social Rio de Janeiro: Zahar Editores. $2^{\text {a }}$. edição. 